\title{
Neoadjuvant Dose-Dense and Dose-Intensified Chemotherapy in Breast Cancer - Review of the Literature
}

\author{
Mattea Reinisch $^{\mathrm{a}}$ Beyhan Ataseven ${ }^{\mathrm{b}}$ Sherko Kümmel ${ }^{\mathrm{a}}$ \\ a Senology, Breast Care Unit, Evangelische Huyssens-Stiftung, Kliniken Essen Mitte, Essen, Germany; \\ ${ }^{b}$ Department of Gynecology and Gynecologic Oncology, Evangelische Huyssens-Stiftung, Kliniken Essen-Mitte, Essen, Germany
}

\section{Keywords \\ Neoadjuvant therapy · Dose-dense chemotherapy . Breast cancer}

\section{Summary}

Dose-dense chemotherapy in the adjuvant and neoadjuvant setting has been intensively examined over the past few decades, and even seems to have become a standard regimen in certain subgroups of patients with increased risk of relapse. Nevertheless, there are conflicting data regarding the absolute benefit of this regimen, especially in the neoadjuvant setting. Pathological complete response ( $p C R$ ) is used as a surrogate marker for disease-free and overall survival. Meta-analyses have recently questioned the use of $\mathrm{pCR}$ as a generalized prognostic tool for all subgroups, but also determined a correlation between treatment effects on the surrogate outcome and the treatment effect on the clinical outcome in the cohort of patients receiving dose-dense chemotherapy. The present paper gives an overview of the definitions of dose-dense and dose-intensified chemotherapy regimens and of the literature for neoadjuvant dose-dense, dose-intensified studies, and summarizes the outcome of these studies.

(c) 2016 S. Karger GmbH, Freiburg

\section{Introduction}

Adjuvant chemotherapy has had a major impact on disease-free survival (DFS) and overall survival (OS) of pre- and postmenopausal women with early-stage breast cancer. The indication for adju- vant chemotherapy was traditionally based on tumor size, lymph node invasion and grading. This has changed over the past few years. The indication for chemotherapy is now predominantly based on tumor biology, simply defined by routinely evaluated parameters such as the hormone receptor status of estrogen (ER) and progesterone (PR), human epidermal growth factor receptor 2 (HER2) amplification and proliferative activity. Recently, gene expression analysis has enlarged the range of prognostic tools.

Neoadjuvant chemotherapy (NACT) has become an acknowledged alternative to adjuvant chemotherapy. NACT has proven to be equally effective with regard to DFS and OS [1], while offering the advantage of monitoring the tumor response under chemotherapy. In addition, a higher tumor response rate translates into a higher rate of breast-conserving treatment and offers the possibility of new therapeutic approaches, e.g. post-neoadjuvant therapies. As a result, the German Working Group on Gynecological Oncology (Arbeitsgemeinschaft Gynäkologische Onkologie, AGO) recommends considering NACT whenever an adjuvant chemotherapy seems to be indicated. However, with regard to the effectivity of new therapeutic regimens it is necessary to generate reliable predictive and prognostic parameters.

There are data supporting the hypothesis that patients with a pathological complete response (pCR) after NACT have a better outcome as compared to patients with residual tumor burden after chemotherapy. Therefore, $\mathrm{pCR}$ has come to be widely accepted as a surrogate marker for DFS and OS. Nonetheless, recent analyses have questioned its general use for all subgroups of breast cancer. Even so, new anti-tumor drugs have received accelerated and preliminary approval based solely on the increased rate of pCR. As an example, pertuzumab, a monoclonal antibody targeting HER2, prevents the dimerization between HER2 and HER3, and has been granted accelerated approval in early-stage breast cancer in combination with trastuzumab and chemotherapy in the neoadjuvant setting $[2,3]$. This accelerated approval has been based on convinc-

\section{KARGER}

Fax +497614520714

\section{(c) 2016 S. Karger GmbH, Freiburg}

1661-3791/16/0111-0013\$39.50/0 
ing data showing an increased pCR rate. However, we do not know whether this translates into better event-free survival (EFS) or OS as the study was not powered for these endpoints.

In triple-negative breast cancer (TNBC) robust evidence exists supporting $\mathrm{PCR}$ as a surrogate marker for OS. Patients in this group with pCR perform excellently over the long term [4]. However is this also true for hormone receptor-positive breast cancer patients with a different underlying biology or patients with germline BRCA mutation? Is pCR a reliable prognostic marker for DFS and OS in all breast cancer subgroups?

In 2014, a meta-analysis [5] was published by the international working group Collaborative Trials in Neoadjuvant Breast Cancer (CTNeoBC), which involved 12 randomized neoadjuvant trials and included more than 12,000 women. This pooled analysis of individual patient data showed a robust validation of $\mathrm{pCR}$ as a prognostic marker, especially in the subgroups of HER2-positive/hormone receptor-negative patients who received trastuzumab (EFS: hazard ratio (HR) $0.15,95 \%$ confidence interval (CI) 0.09-0.27; OS: HR $0.08,95 \%$ CI $0.03-0.22$ ) and of TNBC patients (EFS: HR 0.24, 95\% CI 0.18-0.33; OS: HR 0.16, 95\% CI 0.11-0.25). The degree of attaining $\mathrm{pCR}$ over the past few decades has increased with changes in the drugs available, but this increase has mostly failed to translate directly into an improvement in long-term survival. In the meta-analysis, the trial-level effect on PCR was not a predictor for EFS or OS. The authors gave various reasons for this finding: heterogeneous breast cancer tumor subtypes leading to different responses to the administered treatment, trastuzumab not being given to all HER2-positive patients (due to the different recruitment periods of the trials) and, when trastuzumab was given, it occurred in different settings (adjuvant, neoadjuvant, both) as well as different phases (phase II and phase III). Another explanation might be varying definitions of $\mathrm{PCR}$, as some studies included in situ lesions in their definition or did not take axillary nodal status into account.

A further meta-regression analysis of randomized controlled neoadjuvant trials conducted by Berutti et al. [6] from 2014 included 14,641 patients. They performed an estimation of the logtransformed treatment effect to test the association between treatment effect on the surrogate outcome and treatment effect on the clinical outcome. This analysis supported a weak association between treatment effect on the surrogate outcome and on the clinical outcome with 1 exception: the cohort of patients receiving a dose-dense chemotherapy performed better in the long term, a result that might prove valuable.

The aim of the current paper is to clarify the definition of dosedense and dose-intensified therapy approaches, to summarize the results of the main dose-dense, dose-intensified neoadjuvant trials, and to review the outcome in comparison with standard-dosed neoadjuvant trials.

Since the definition of dose-dense and dose-intensified chemotherapy seems to be a common source of confusion, it would be meaningful to start with the definitions and the underlying hypothesis of efficacy.

\section{(A) Standard dosing:}

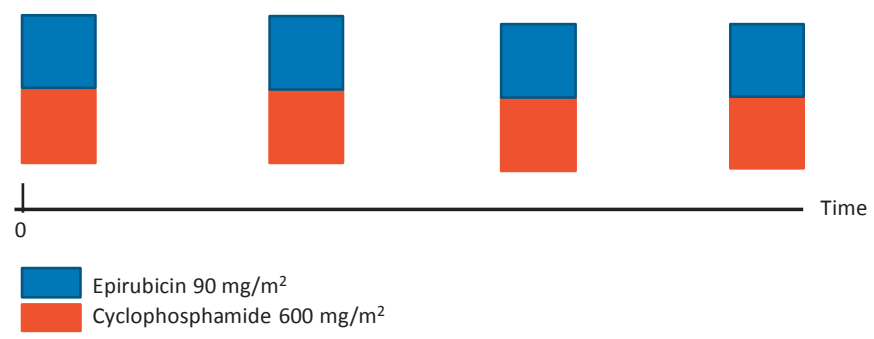

(B) Dose-dense regimen:

standard dosing, shorter intervals

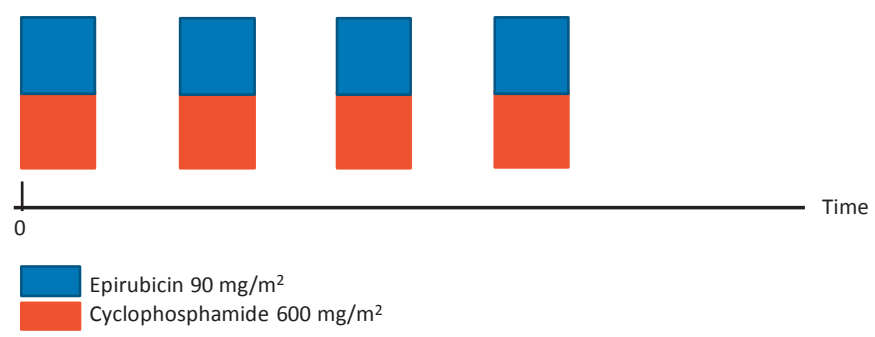

(C) Dose-intensified regimen:

increased dosing, shorter intervals

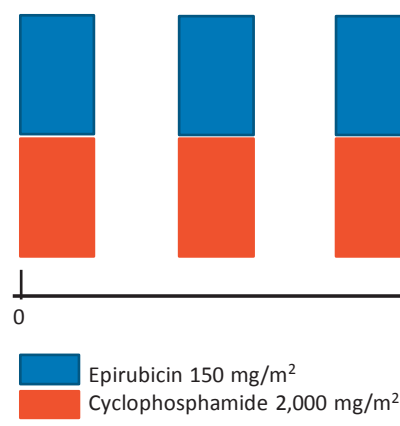

Fig. 1. Standard chemotherapy (A) versus dose-dense chemotherapy (B) and dose-intensified chemotherapy (C).

Chemotherapy with epirubicin/cyclophosphamide (EC) is used as an example to clarify the dosing as well as the timing.

\section{Definitions and Rationale of Dose-Dense and Dose- Intensified Chemotherapy}

Delivering higher doses of chemotherapy can be achieved either by increasing the absolute dose of drug per square meter or by reducing the intervals between cycles or by both procedures.

Dose-dense chemotherapy regimens administer the standard dose at shorter intervals without increasing the drug concentration per cycle, whereas dose-intensified regimens increase not only the total dose per body surface area but also shorten the intervals between the applied doses. Figure 1 depicts the different approaches in comparison to the standard dosing.

This approach needs to be differentiated from a dose-dense, dose-tailored approach and a high-dose chemotherapy. However, as these regimens are not part of this present paper we do not go into details here. 
Table 1. Description of the study regimens described in this paper

\begin{tabular}{|c|c|c|c|c|c|}
\hline Trial & $\begin{array}{l}\text { First author } \\
\text { [Ref.] }\end{array}$ & $\begin{array}{l}\text { Dose dense } \\
\text { or dose } \\
\text { intensified }\end{array}$ & $\begin{array}{l}\text { Dosing of the } \\
\text { experimental arm, } \\
\mathrm{mg} / \mathrm{m}^{2}\end{array}$ & $\begin{array}{l}\text { Dosing of the } \\
\text { standard arm, } \\
\mathrm{mg} / \mathrm{m}^{2}\end{array}$ & Supplements \\
\hline $\begin{array}{l}\text { AGO 1 } \\
\text { Phase III }\end{array}$ & Untch [12] & $\begin{array}{l}\text { dose } \\
\text { intensified }\end{array}$ & $6 \times$ E 150 P 250 q2w & $\begin{array}{l}4 \times \text { E } 90, \text { P } 175 \\
\text { q3w }\end{array}$ & $\begin{array}{l}\text { All after surgery: CMF } \\
\text { ddEP + G-CSF }\end{array}$ \\
\hline $\begin{array}{l}\text { GeparDuo } \\
\text { Phase III }\end{array}$ & $\begin{array}{l}\text { Von } \\
\text { Minckwitz } \\
{[13]}\end{array}$ & dose dense & $4 \times$ A 50 DOC $75 \mathrm{q} 2 \mathrm{w}$ & $\begin{array}{l}6 \times \text { A } 60 \text { C } 600 \\
q 3 w \\
4 \times \text { DOC } 100 q 3 w\end{array}$ & $\mathrm{ADOC}+\mathrm{G}-\mathrm{CSF}$ \\
\hline $\begin{array}{l}\text { Prepare } \\
\text { Phase III }\end{array}$ & Untch [14] & $\begin{array}{l}\text { dose } \\
\text { intensified }\end{array}$ & $\begin{array}{l}3 \times \text { E } 150 \text { q2w } \\
3 \times \text { P } 225 \text { q } 2 w \text {, followed } \\
\text { by } 3 \times \text { C } 500 \text { M } 40 \\
\text { F } 600 \text { d } 1+8 \text { q } 4 \text { w }\end{array}$ & $\begin{array}{l}\text { E } 90 \text { C } 600 \text { q3w } \\
\text { followed by } \\
4 \times \text { P } 175 \text { q3w }\end{array}$ & $\begin{array}{l}\text { diEP + G-CSF } \\
2^{\text {nd }} \text { randomization to } \\
\text { darbepeotin alpha: } \\
\text { no benefit seems to } \\
\text { compromise OS }\end{array}$ \\
\hline Phase III & Baldini [17] & dose dense & C 600 E 60 F $600 \mathrm{q} 2 \mathrm{w}$ & $\begin{array}{l}\text { C } 600 \text { E } 60 \text { F } 600 \\
q 3 w\end{array}$ & $\begin{array}{l}\text { q2w + G-CSF, both arms } \\
\text { continued with adjuvant } \\
\text { chemotherapy }\end{array}$ \\
\hline $\begin{array}{l}\text { EORTC- } \\
\text { NCIC-SAKK } \\
\text { Phase III }\end{array}$ & $\begin{array}{l}\text { Therasse } \\
{[16]}\end{array}$ & $\begin{array}{l}\text { dose } \\
\text { intensified }\end{array}$ & $\begin{array}{l}6 \times C 75 \text { (p.o. d 1-14) } \\
\text { E } 60(d 1+8) \\
\text { F } 50(d 1+8) q 4 w\end{array}$ & $\begin{array}{l}6 \times \text { E } 120 \text { C } 830 \\
q 2 w\end{array}$ & G-CSF for EC \\
\hline $\begin{array}{l}\text { SWOG } 0012 \\
\text { Phase III }\end{array}$ & Ellis [21] & $\begin{array}{l}\text { dose } \\
\text { intensified }\end{array}$ & $\begin{array}{l}\text { 15× ddA } 24 \text { C } 60 \text { (d p.o. } \\
\text { q1w) } \\
\text { followed by } 12 \times \text { P } 80\end{array}$ & $\begin{array}{l}5 \times \text { A } 60 \text { C } 600 \\
\text { q } 3 w \\
\text { followed by } \\
12 \times \text { P } 80\end{array}$ & $\begin{array}{l}\text { G-CSF for the weekly dd } \\
\text { AC }\end{array}$ \\
\hline $\begin{array}{l}\text { GeparSixto } \\
\text { Phase II }\end{array}$ & $\begin{array}{l}\text { Von } \\
\text { Minckwitz } \\
{[23,24]}\end{array}$ & $\begin{array}{l}\text { dose dense } \\
\text { both arms }\end{array}$ & $\begin{array}{l}\text { 18× P } 80 \text { q1w + } \\
\text { M } 20 \text { q1w + } \\
\text { Cb AUC } 1.5 \text { q1w } \\
\text { if HER2 pos: + Trast/ } \\
\text { Lap } \\
\text { if TNBC: + bevacizumab }\end{array}$ & $\begin{array}{l}18 \times \text { P } 80 \text { q1w } \\
+ \text { M } 20 \text { q1w } \\
\text { if HER2 pos: } \\
+ \text { Trast/Lap } \\
\text { if TNBC: } \\
\text { + bevacizumab }\end{array}$ & No G-CSF \\
\hline
\end{tabular}

$\mathrm{E}=$ epirubicin, $\mathrm{P}=$ paclitaxel, $\mathrm{C}=$ cyclosphosphamide, $\mathrm{M}=$ methotrexate, $\mathrm{F}=5$-fluorouracil, $\mathrm{A}$ = adriamycin, $\mathrm{ns}$ = not significant, sig = significant, $\mathrm{DOC}=$ docetaxel, $\mathrm{M}=$ non-pegylated liposomal doxorubicin, $\mathrm{Cb}=$ carboplatin, Trast $=$ trastuzumab, Lap = lapatinib, $\mathrm{d}=$ day, p.o. $=$ orally, $\mathrm{OS}=$ overall survival, $\mathrm{G}-\mathrm{CSF}=$ granulocyte-colony-stimulating factor.

\section{Rationale for Dose-Dense or Dose-Intensified Chemotherapy Regimens}

In vivo data show that there is a steep dose-response curve in drug-sensitive tumors. Thus, halving the dose reduced the tumor cell killing many times. In a clinical setting, this means that reducing the chemotherapy dose could lead to ineffective treatment [7]. The opposite is hypothesized to be the case for increasing the dose and/or shortening the administration intervals: by shortening the time between doses, the time for recovery and further cell division and cell growth is also kept short. This increases the amount of cells destroyed.

Two different hypotheses provide the foundation for alternative dosing. There is the Norton-Simon hypothesis, which provides the basic concept for this approach. It says 'chemotherapy results in a rate of regression of tumor volume that is proportional to the rate of growth for an unperturbed tumor of that size' [8]. Small tumors grow faster than larger ones, as non-exponential Gompertzian kinetics apply. Cytoreductive therapy will, therefore, lead to an increase in the regrowth between cycles, as the tumors will have been reduced in size. Subsequent chemotherapy must be delivered sequentially at the shortest possible intervals to be most effective [9].

Another hypothesis providing the rationale for this approach is the Goldie-Coldman hypothesis [10]. It says that a spontaneous development of drug-resistant cells occurs after exposure of the tumor to cytotoxic agents. Drug-resistant mutations arise with a measurable frequency. The larger the tumor burden, the more likely a mutation will occur. This hypothesis predicts that early introduction of dose-intensive alternating agents is most likely to prevent a large number of resistant clones, which would increase efficacy. These 2 hypotheses have led in the last few decades to a variety of clinical trials investigating dose-dense, dose-intensified chemotherapy regimens for both early and locally advanced breast cancer. Tables 1 and 2 depict the main differences in the study design and the outcome

\section{Neoadjuvant Clinical Trials Investigating the Dose- Dense, Dose-Intensified Approach}

In 1989, Hryniuk and Levine [11] published an analysis of 6,106 breast cancer patients with stage II disease, who received a dose-in- 
Table 2. Parameters of pCR, DFS and OS between the experimental and the standard regimens

\begin{tabular}{|c|c|c|c|c|c|}
\hline $\begin{array}{l}\text { Trial } \\
\text { [Ref.] }\end{array}$ & Patients, $\mathrm{n}$ & Schedule & $\begin{array}{l}\text { pCR rate (experimental } \\
\text { vs. standard) }\end{array}$ & $\begin{array}{l}\text { DFS (experimental } \\
\text { vs. standard) }\end{array}$ & $\begin{array}{l}\text { OS } \\
\text { (experimental vs } \\
\text { standard) }\end{array}$ \\
\hline $\begin{array}{l}\mathrm{AGO} 1 \\
\quad[12]\end{array}$ & 668 & $\begin{array}{l}\text { ddEP } \rightarrow \text { CMF vs. } \\
\text { EP } \rightarrow \text { CMF }\end{array}$ & $\begin{array}{l}\text { ypT0, ypN0/ pNx: } 18 \% \\
\text { vs. } 10 \%(\mathrm{p}=\mathrm{sig})\end{array}$ & 5 years: $70 \%$ vs. $59 \%$ & 5 years: $83 \%$ vs. $77 \%$ \\
\hline $\begin{array}{c}\text { GeparDuo } \\
\text { [13] }\end{array}$ & 913 & $\begin{array}{l}\text { ADOC } \\
\text { AC-DOC }\end{array}$ & $\begin{array}{l}7 \% \text { vs. } 14 \% \\
P=0.0011\end{array}$ & not reported & not reported \\
\hline $\begin{array}{r}\text { Prepare } \\
{[14]}\end{array}$ & 736 & $\begin{array}{l}\text { ddET } \rightarrow \text { CMF } \\
\text { EC-T }\end{array}$ & $\begin{array}{l}\text { ypT0, ypN0/ pNx: } 18 \% \\
\text { vs. } 12 \% \text { p = sig }\end{array}$ & $\begin{array}{l}3 \text { years: } 78.8 \% \text { vs. } \\
75.8 \% \\
\text { p=ns. }\end{array}$ & \\
\hline $\begin{array}{l}\text { EORTC- } \\
\text { NCIC-SAKK } \\
\quad[16]\end{array}$ & 448 & $\begin{array}{l}\mathrm{diEC} \\
\mathrm{CEF}\end{array}$ & $\begin{array}{l}\text { clinical complete } \\
\text { response } \\
26.5 \% \text { vs. } 31.3 \% \\
\text { pCR not reported }\end{array}$ & $\begin{array}{l}5.5 \text { years: } \\
33.7 \text { months vs. } \\
34 \text { months } \\
\mathrm{p}=\mathrm{ns}\end{array}$ & $\begin{array}{l}5.5 \text { years } \\
51 \% \text { vs. } 53 \% \\
\text { p = ns }\end{array}$ \\
\hline $\begin{array}{r}\text { Baldini } \\
{[17]}\end{array}$ & 150 & $\begin{array}{l}\text { ddCEF q2w } \\
\text { CEF q3w }\end{array}$ & $\begin{array}{l}\text { ypT0, ypN0, ypTis, } \\
\text { ypN0: } 4.1 \text { vs. } 2.6 \\
\text { p = ns. }\end{array}$ & $60 \%$ vs $58 \% \mathrm{p}=\mathrm{ns}$ & $\begin{array}{l}5 \text { years: } 54 \% \text { vs. } 52 \% \\
\text { p = ns. }\end{array}$ \\
\hline $\begin{array}{l}\text { SWOG } 0012 \\
\quad[21]\end{array}$ & 372 & $\begin{array}{l}12 \times \mathrm{ddA} \rightarrow 12 \times \mathrm{P} \\
5 \times \mathrm{A} \rightarrow 12 \times \mathrm{P}\end{array}$ & $\begin{array}{l}\text { ypT0, ypN0/ pNx: } \\
\text { p = ns }\end{array}$ & $\mathrm{p}=\mathrm{ns}$ & $\mathrm{p}=\mathrm{ns}$ \\
\hline $\begin{array}{r}\text { GeparSixto } \\
{[23,24]}\end{array}$ & 595 & $\begin{array}{l}18 \times \text { P } 80 \text { q1w+ } \\
\text { NPLD } 20 \mathrm{q} 1 \mathrm{w} \\
+/- \\
\text { Cb AUC } 1.5 \mathrm{q} 1 \mathrm{w}\end{array}$ & $\begin{array}{l}\text { all: } 36.9 \% \\
\text { PMCb } 43.7 \% \\
\text { p = ns. } \\
\text { in TNBC: } \\
\text { PM } 36.9 \% \\
\text { PMCb } 53.2 \%, p=0.005 \\
\text { in HER2 pos: } \\
\text { PM } 36.8 \% \text { PMCb 32.8\%, } \\
\text { p = } 0.6\end{array}$ & $\begin{array}{l}\text { DFS after } 3 \text { years }-\mathrm{F} \\
\text { PMCb vs. } \mathrm{PM} \\
\text { all: } 84.7 \text { vs. } 81.0, \\
\text { p }=0.31 \\
\text { HER2 pos.: } \\
86.7 \text { vs. } 83.4 \\
\text { p }=0.37 \\
\text { TNBC: } \\
85.8 \text { vs. } 76.1, \mathrm{p}=0.03\end{array}$ & not published \\
\hline
\end{tabular}

$\mathrm{pCR}=$ pathological complete response, $\mathrm{DFS}=$ disease-free survival, $\mathrm{OS}=$ overall survival, $\mathrm{E}=$ epirubicin, $\mathrm{P}=$ paclitaxel, $\mathrm{C}=$ cyclosphosphamide, $\mathrm{M}=$ methotrexate, $\mathrm{F}=5$-fluorouracil, $\mathrm{A}=$ adriamycin, $\mathrm{ns}=$ not significant, $\mathrm{sig}=$ significant, $\mathrm{vs}=$ versus $\mathrm{DOC}=$ docetaxel, $\mathrm{M}=$ non-pegylated liposomal doxorubicin, $\mathrm{Cb}=$ carboplatin, Trast = trastuzumab, Lap = lapatinib, $\mathrm{d}=$ day. tensified chemotherapy regimen containing cyclophosphamide, methotrexate, and fluorouracil (CMF). In this work, the applied dose intensity showed an independent significant correlation with relapse-free survival in the multivariate analysis. They demonstrated a clear-cut relationship between relapse-free survival and dose intensity in trials for patients younger than 50 years with both 1-3 and more than 3 positive nodes. This work and others led to the development of further adjuvant and neoadjuvant trials investigating the impact of dose-dense and dose-intensified chemotherapy in patients with early or locally advanced non-metastasized breast cancer.

The AGO-1 trial [12] was the first German neoadjuvant randomized phase III study evaluating the role of dose-dense chemotherapy in patients with early breast cancer; it included 668 evaluable patients, recruiting from 1998 to 2002 . In this study the efficacy of dose-dense epirubicin $\left(150 \mathrm{mg} / \mathrm{m}^{2}\right.$; every 2 weeks (q2w)) and paclitaxel $\left(250 \mathrm{mg} / \mathrm{m}^{2}, \mathrm{q} 2 \mathrm{w}\right)$ (ddEP) was investigated, comparing this to the standard dosed therapy of 4 cycles of epirubicin/paclitaxel $\left(90 / 175 \mathrm{mg} / \mathrm{m}^{2}, \mathrm{q} 3 \mathrm{w}\right)(\mathrm{EP})$. Patients in the ddEP cohort received filgrastim $(5 \mathrm{mg} / \mathrm{kg})$ subcutaneously (s.c.) on days 3-10 of each cycle. After surgery, all patients received 3 cycles of cyclophosphamide/methotrexate/fluorouracil (500/40/600 mg/m² given on days 1 and 8 of each cycle every 4 weeks) (CMF).

The $\mathrm{pCR}$ rate (ypT0/ypTis, $\mathrm{pNx}$ ) in the ddEP group was significantly higher as compared to the conventionally dosed EP group
( $18 \%$ vs. $10 \%, \mathrm{p}=0.008)$ and remained significant when a stricter pCR definition was used: ypT0, ypN0 ( $12 \%$ vs. $6 \%, \mathrm{p}=0.011$ ).

After a median follow-up of 55 months, the increased pCR in the dose-dense cohort led to a significant increase of the DFS (76\% vs. $68 \%$ after 3 years, $70 \%$ vs $59 \%$ at 5 years, HR $0.71 ; 95 \%$ CI: $0.54-$ $0.92 ; \mathrm{p}=0.011)$ and OS: (90\% vs. $85 \%$ after 3 years and $83 \%$ vs. $77 \%$ after 5 years HR 0.83; 95\% CI 0.69-0.99; $\mathrm{p}=0.041$ ).

Patients in the dose-dense arm had significantly more non-hematological toxicities but similar neutropenia and infection rates. In addition, the incidence of thrombopenia, stomatitis, sensory neurotoxicity, nausea and vomiting significantly increased with the dose-dense therapy. This study provided support for administering epirubicin and paclitaxel in higher doses and at shorter intervals every 2 weeks as compared to every 3 weeks.

The GeparDuo [13] study was a randomized, multicenter neoadjuvant phase III study, recruiting from June 1999 to September 2001, including 913 women with untreated operable breast cancer, of whom 904 patients were included in the analysis. They were randomly assigned to receive either doxorubicin $\left(50 \mathrm{mg} / \mathrm{m}^{2}\right)$ plus docetaxel $\left(75 \mathrm{mg} / \mathrm{m}^{2}\right)$ every 14 days for 4 cycles with filgrastim support (ADOC), or doxorubicin $\left(60 \mathrm{mg} / \mathrm{m}^{2}\right)$ plus cyclophosphamide $\left(600 \mathrm{mg} / \mathrm{m}^{2}\right)$ every 21 days, followed by docetaxel $\left(100 \mathrm{mg} / \mathrm{m}^{2}\right)$ every 21 days for 4 cycles each (AC-DOC). The primary endpoint was the $\mathrm{pCR}$ rate (invasive and non-invasive) in the breast and ax- 
illary nodes. In addition, all patients, irrespective of their hormone receptor status, received tamoxifen daily simultaneously with the applied chemotherapy until surgery.

The GeparDuo study failed to demonstrate a benefit for neoadjuvant, dose-dense therapy with ADOC treatment. In retrospect, however, this is not surprising as the 2 regimens not only had different dose densities, they also differed in terms of dose intensity, cumulative doses, number of chemotherapy drugs, and overall duration of treatment ( 8 weeks vs. 24 weeks). It is, therefore, not surprising that the short, dose-dense therapy was associated with a lower pCR rate (7\% vs. $14 \%)$.

The Prepare Trial [14] was a multicenter, prospective, randomized, open-label phase III trial recruiting from June 2002 to February 2005, which enrolled 736 female breast cancer patients. Of these, 714 patients were evaluable for the final report. The trial was set up to evaluate the efficacy of pre-operative, dose-dense, dose-intensified chemotherapy with 3 cycles of epirubicin (150 mg/ $\left.\mathrm{m}^{2} ; \mathrm{q} 2 \mathrm{w}\right)$ followed by 3 cycles of paclitaxel $\left(225 \mathrm{mg} / \mathrm{m}^{2} ; \mathrm{q} 2 \mathrm{w}\right)$, followed by 3 cycles of a combination chemotherapy with cyclophosphamide/methotrexate/5-fluorouracil $\left(500 / 40 / 600 \mathrm{mg} / \mathrm{m}^{2}\right.$ on days 1 and 8 every 4 weeks for 3 cycles (ddET $\rightarrow \mathrm{CMF})$ ), as with the AGO-1 trial. This arm was compared to 4 cycles of standard-dosed epirubicin/cyclophosphamide $\left(90 / 600 \mathrm{mg} / \mathrm{m}^{2} ; \mathrm{q} 3 \mathrm{w}\right)$ followed by 4 cycles of paclitaxel $\left(175 \mathrm{mg} / \mathrm{m}^{2} ; \mathrm{q} 3 \mathrm{w}\right)(\mathrm{EC} \rightarrow \mathrm{T})$. In addition, the patients were randomly assigned to receive darbepoetin alfa or no darbepoetin treatment. Additionally, patients in the ddET $\rightarrow \mathrm{CMF}$ arm received pegfilgrastim (6 mg s.c. on day 2 ) in cycles 1-6 (while on ddET). pCR was defined as ypT0, ypN0/is.

The Prepare Trial showed a non-significant improvement of DFS and OS for the dose-intensified anthracycline-taxane-containing chemotherapy (3-year DFS of $78.8 \%$ for ddET $\rightarrow$ CMF vs. $75.8 \%$ for $\mathrm{EC} \rightarrow \mathrm{T}$, HR 1.14; $95 \% \mathrm{CI} 0.85-1.52 ; \mathrm{p}=0.37$ ), although the $\mathrm{pCR}$ rate increased significantly from $12 \%$ to $18 \%(\mathrm{p}=0.0176)$. The addition of darbepoetin alpha did not affect the pCR rate; it led, however, to an increase in the rate of thromboembolic events (3\% vs. $6 \% ; \mathrm{p}=0.055)$ and seemed to compromise the DFS [15].

The EORTC-NCIC-SAKK multicenter study [16] was a prospective, randomized neoadjuvant trial, designed to assess the efficacy of a standard-dosed anthracycline-based regimen (CEF) as compared with a dose-intensified anthracycline (ddEC) regimen in locally advanced, non-metastasized breast cancer; 448 patients were included between 1993 and 1996. Patients were randomly assigned to 6 cycles of cyclophosphamide $\left(C ; 75 \mathrm{mg} / \mathrm{m}^{2}\right.$ orally days 1-14), epirubicin ( $\mathrm{E} ; 60 \mathrm{mg} / \mathrm{m}^{2}$ intravenously (i.v.) days 1 and 8 ), and fluorouracil ( $F ; 500 \mathrm{mg} / \mathrm{m}^{2}$ i.v. days 1 and 8 ) every 4 weeks (6× CEF) versus 6 cycles of epirubicin/cyclophosphamide $\left(120 / 830 \mathrm{mg} / \mathrm{m}^{2} ; \mathrm{q} 2 \mathrm{w}\right)(6 \times \mathrm{ddEC})$. The median follow-up was 5.5 years. The median PFS and OS did not show a significant difference between the study arms (PFS: 34 and 33.7 months for CEF and EC respectively; $\mathrm{p}=0.68$ ), and the 5 -year OS was also not significantly different ( $53 \%$ vs. $51 \%$; $\mathrm{p}=0.94$ ). The study did not show any benefit in increasing the dosing of EC in comparison to the standard dosing of CEF in patients with locally advanced, non-metastasized breast cancer.
The toxicity did not significantly differ between the treatment arms. The incidence of grade 3-4 thrombopenia, neutropenia and anemia was higher in patients in the ddEC arm, but the rate of febrile neutropenia of grade 3 and 4 did not increase in the dosedense treatment arm; nor did the rate of hospitalization. However, the quality of life scores for the first 3 months under treatment were lower in the group of patients receiving ddEC, although it returned to the baseline after 3 months, whereas the score remained stable throughout the treatment for patients receiving CEF. No statistically significant difference regarding the quality of life was observed between the treatment groups 1 year after treatment.

Baldini et al. [17] investigated in a randomized, neoadjuvant phase III trial the impact of dose dense CEF (cyclophosphamide $600 \mathrm{mg} / \mathrm{m}^{2}$, epirubicin $60 \mathrm{mg} / \mathrm{m}^{2}$ and 5-fluorouracil $600 \mathrm{mg} / \mathrm{m}^{2}$ ) given every 2 weeks in comparison with the same dosing given every 3 weeks for a total of 3 cycles followed by surgery; 150 patients were recruited between 1992 and 1997. After surgery, patients continued to receive CEF alternated with CMF (cyclophosphamide $600 \mathrm{mg} / \mathrm{m}^{2}$, methotrexate $40 \mathrm{mg} / \mathrm{m}^{2}$, 5-fluorouracil $600 \mathrm{mg} / \mathrm{m}^{2}$ day 1) for 6 cycles. The pCR rate, DFS and OS did not significantly differ between the 2 treatment arms even though the dose was accelerated by $30 \%$. In total, the toxicity was considered to be mild with no reported febrile neutropenia or hospitalization due to toxicity. In the dose-dense arm, patients received granulocyte-colony-stimulating factor (G-CSF) support. No major differences were seen between the treatment arms.

The impact of the paclitaxel dose and the paclitaxel dose intensity was evaluated by Green et al. [18] in a neoadjuvant, randomized phase II study. Between 1998 and 2001, 480 patients were included in the study. Patients with node-positive or node-negative disease were randomly assigned to receive either paclitaxel every 3 weeks $\left(225 \mathrm{mg} / \mathrm{m}^{2}\right)$ administered as a continuous i.v. infusion over a period of $24 \mathrm{~h}$ or $12 \times$ paclitaxel weekly. The latter group was divided according to the risk of relapse based on the nodal status. Node-negative patients $(\mathrm{n}=148)$ received $12 \times$ paclitaxel weekly $\left(80 \mathrm{mg} / \mathrm{m}^{2}\right)$ without interruption, node-positive patients $(\mathrm{n}=110)$ received dose-intense weekly paclitaxel $\left(175 \mathrm{mg} / \mathrm{m}^{2}\right)$ for 3 weeks followed by a 1-week break for 4 cycles (12 infusions of paclitaxel in total). Thereafter all patients received 4 cycles of fluorouracil/ doxorubicin/cyclophosphamide (FAC) in standard doses every 3 weeks, which was followed by breast surgery. The weekly application of paclitaxel led to a higher pCR rate as compared to the 3 -weekly intervals $(28.2 \%$ vs. $15.7 \%$; $p=0.02)$, irrespective of the lymph node status. Patients with hormone receptor-negative disease had a significantly higher pCR rate than patients with hormone receptor-positive disease $(\mathrm{p}=0.007)$. The rate of toxicity differed between the treatment arms: patients in the dose-dense weekly arm experienced significantly more neurotoxicity. Paclitaxel $\left(80 \mathrm{mg} / \mathrm{m}^{2}\right)$ administered weekly was well tolerated and induced fewer side effects than paclitaxel administered every 3 weeks.

The increased tolerability of the weekly regimen was also shown by Walker et al. [19]. In this study 96 patients were included between 2000 and 2002 and were randomly assigned to receive either 12 cycles of weekly docetaxel $\left(33 \mathrm{mg} / \mathrm{m}^{2}\right)$ or docetaxel $\left(100 \mathrm{mg} / \mathrm{m}^{2}\right)$ 
every 3 weeks for 4 cycles The 2 regimens showed a comparable pCR rate $(20 \%$ in the weekly and $27 \%$ in the 3 -weekly groups, $\mathrm{p}=0.43$ ). The toxicity was also comparable between the treatment arms apart from a significant increase of the rate of neuropathy in the 3-week arm ( $\mathrm{p}=0.008)$.

Finally, the impact of different taxanes and application schedules was evaluated in a phase III study in the adjuvant setting, demonstrating in the long-term follow-up an improved outcome for the weekly paclitaxel regimen, especially in the TNBC [20] cohort.

The impact of alternating anthracycline dosing was investigated in the SWOG 0012 study [21]. Eligible patients received either $5 \times$ doxorubicin every 3 weeks $\left(60 \mathrm{mg} / \mathrm{m}^{2}\right)$ or $12 \times$ weekly $\left(24 \mathrm{mg} / \mathrm{m}^{2}\right)$ with G-CSF support. All patients had subsequent weekly paclitaxel for 12 weeks before surgery. The pCR did not differ between the treatment groups stratified by disease type $(p=0.42)$. OS and DFS also did not differ for the regimens ( $\mathrm{p}=0.37$ and $\mathrm{p}=0.87$, respectively).

Another trial investigating the neoadjuvant dose-dense approach is the currently recruiting GeparOcto study (GBG 84), a neoadjuvant randomized phase III trial. In this study, both treatment arms include a dose-dense regime, in which patients are randomly assigned to receive either ETC based on the adjuvant AGO ETC study or 18 weeks treatment with paclitaxel weekly (P) $\left(80 \mathrm{mg} / \mathrm{m}^{2}\right) /$ non-pegylated liposomal doxorubicin (M) $\left(20 \mathrm{mg} / \mathrm{m}^{2}\right.$ once a week) based on the neoadjuvant GeparSixto study [22]. Both arms receive the dual HER2 blockade with trastuzumab and pertuzumab ( $\mathrm{q} 3 \mathrm{w}$ ) in case of HER2 positivity, or carboplatin (AUC 1.5) in case of a triple-negative subgroup. Results are pending as this study is still recruiting.

The dose-dense PM backbone was administered in both arms in the GeparSixto study, a neoadjuvant, randomized phase II study. In this trial, patients with HER2-positive and triple-negative disease $(n=595)$ were included. An aim of this trial was to investigate the therapeutic benefit of the addition of weekly carboplatin. All patients with HER2-positive disease additionally received the dual HER2 blockade consisting of trastuzumab and pertuzumab. Over the total study cohort (containing both subgroups) the addition of carboplatin to PM did not lead to a significant increase in the primary study endpoint pCR rate (ypT0 ypN0) (43.7\% vs $36.9 \%$, $\mathrm{p}=0.107)$. However, considering both subgroups separately, a substantial increase of pCR rate was detected for patients with TNBC by the addition of carboplatin ( $36.9 \%$ vs. $53.2 \%, \mathrm{p}=0.005)$, which translates into an increased DFS $(85.8 \%$ vs $76.1 \%, \mathrm{p}=0.03)$. The addition of carboplatin did not increase the rate of $\mathrm{pCR}$ in patients with HER2-positive breast cancer [23]. After a median follow-up of 35 months, the addition of carboplatin improved DFS in patients with TNBC (HR 0.56, p = 0.035) but showed no effect in patients with HER2-positive disease (HR 1.33, $\mathrm{p}=0.372$, test for interaction $\mathrm{p}=0.046)$ [24]. The impact of the addition of carboplatin and bevacizumab to a dose-dense regimen consisting of paclitaxel weekly $\left(80 \mathrm{mg} / \mathrm{m}^{2}\right)$ followed by EC $\left(90 / 600 \mathrm{mg} / \mathrm{m}^{2}\right)$ given every 2 weeks was investigated by Sikov et al. [25], demonstrating a better DFS and OS for patients having a pCR after a median follow-up of 39 months. The addition of carboplatin or bevacizumab did not have a significant impact on the DFS or OS.
Combining the information on toxicity from the studies above, the dose-dense approach seems to be a well-tolerated therapy in patients with a high tumor burden. Increased toxicity needs to be taken into consideration and G-CSF support is mandatory in this schedule. Nonetheless, despite the care that has to be exercised, a dose-dense chemotherapy regimen is feasible. However, there are few long-term data regarding second malignancies. Data for the long-term side effects of dose-dense, dose-intensified treatment are given in the adjuvant ETC trial [26]. Here, the total rate of second malignancies was reported to be $0.9 \%(n=11)$ during follow-up. With 8 events, the frequency was higher in the dose-dense, doseintensified arm, but this difference did not reach statistical significance $(p=0.23)$. Apart from the induction of second malignancies, the long-term cardiac side effects of anthracyclines are a matter of concern. In the ETC trial no significant increase in congestive cardiac failure grade 3 was observed.

\section{Conclusions}

The immediate evaluation of the response to the applied NACT measured as PCR is that of a great advantage of NACT. Nevertheless, the question of whether the achievement of a pCR translates into a better DFS and OS is still open. The optimization of neoadjuvant therapies with the aim of improving long-term survival is therefore crucial. However, there are still insufficient biomarkers for predicting the long-term outcome for all subgroups. The pCR rate seems to be a reliable prognostic marker of treatment efficacy in some breast cancer subgroups. Patients with a TNBC achieving a pCR have a significantly better DFS and OS as compared to patients without a pCR [4]. This strict correlation does not generally apply to other subgroups.

Recent published meta-analyses have failed to establish a general use of the pCR as surrogate marker for DFS and OS as a triallevel endpoint $[5,6,27]$. Therefore, it is essential to differentiate the use of the pCR between a patient-level and trial-level endpoint [27]. The fact that those 2 analyses do not necessarily give the same answers has different reasons. The cohort of included patients differed between the trials. The possibility of implementing new therapy options within clinical trials such as CDK 4/6 inhibitors, PARP inhibitors or further anti-HER2 agents as post-neoadjuvant treatment to further increase long-term survival in patients with high tumor burden after NACT has changed over the past few decades. Better treatment options if disease progression occurs may also influence the value of $\mathrm{pCR}$ as a surrogate for OS.

Based on the meta-analysis by Berruti et al. [6], the pCR rate seemed to be a surrogate marker on the trial level for DFS and OS only for the dose-dense studies. The authors noted that this correlation might be due to the larger effect seen on the pCR rate. The population included in that study varied not only within a particular trail but even more between the trials. For example, the EORTC-NCIC-SAKK multicenter study [16] included only patient with locally advanced, non-metastasized breast cancer. According to the Norton Simon and the Goldie-Coldman hypotheses, patients 
with small tumors benefit from a dose-dense chemotherapy as replication in these patients is increased compared to patients with larger tumors. Therefore, inducing a pCR in patients with a smaller tumor burden (irrespectively of the underlying biology) is more likely than in patients with advanced disease and a higher tumor burden. The AGO-1 trail included patients with inflammatory disease, the GeparDuo study included only patients with a cT3 disease. This difference is shown in tables 1 and 2. Furthermore, some of the studies were conducted at a time when anti-HER2-therapies were not available, or had not yet been generally integrated into the trials or clinical adjuvant routine treatment. The proliferative activity or the HER2 status did not influence the decision to include patients in a trial. Adjuvant endocrine therapy is 1 option as post-neoadjuvant therapy, which all hormone receptor-positive patients receive nowadays and the choice of agents has increased over the last few years. The addition of aromatase inhibitors to the selection of anti-hormonal therapy has improved its efficacy [28]. Recently, more modern therapy options have become available for the different subgroups. Therapies with CDK 4/6 inhibitors, PARP inhibitors or pertuzumab are available within studies and these post-neoadjuvant therapies might also dilute the DFS/OS results. Importantly, it should be noted that hardly any of the studies were powered to detect a difference in the DFS or OS.

Thanks to a more detailed pre-therapeutic analysis of the tumor, today a patient's selection for neoadjuvant therapy differs significantly from that of the past. Initially, the evaluation of the potential impact of dose-dense chemotherapy was mainly based on tumor size and nodal status. Proliferative activity measured by Ki67 or the HER2 as a tool for defining the aggressiveness of a tumor was not part of the clinical routine. Today, the indication for or against chemotherapy and, subsequently, for or against a dose-dense regimen, is based not only on tumor size and nodal status, but more importantly on the underlying biology of the tumor.

Therefore, it is not possible to draw reliable conclusions from the results of the studies described above. If possible, patients should be treated within clinical trials, especially if dose-dense, dose-intensified regimens with the addition of new drugs are available, as this is the only possibility for reliably evaluating not only the efficacy, but also the short- and long-term side effects.

In conclusion, the recently published meta-analyses $[5,6]$ questioning the value of $\mathrm{pCR}$ as a surrogate marker for DFS and OS have started a debate. Until this question is fundamentally solved, neoadjuvant studies should continue to follow patients to observe the DFS and OS rate and to power their studies sufficiently to gain a reliable assessment of the long-term outcome and not only the pCR.

\section{Disclosure Statement}

Mattea Reinisch and Beyhan Ataseven declare no conflict of interest. Sherko Kümmel declares research funding from Roche; honoraria from Roche, Celgene, Novartis, Amgen and Genomic Health; and a consulting or advisory role for Roche.

\section{References}

1 Rastogi P, Anderson SJ, Bear HD, et al.: Preoperative chemotherapy: Updates of National Surgical Adjuvant Breast and Bowel Project Protocols B-18 and B-27. J Clin Oncol 2008;26:778-785

2 Gianni L, Pienkowski T, Im YH, et al.: Efficacy and safety of neoadjuvant pertuzumab and trastuzumab in women with locally advanced, inflammatory, or early HER2-positive breast cancer (NeoSphere): A randomised multicentre, open-label, phase 2 trial. Lancet Oncol 2012;13:25-32.

3 Schneeweiss A, Chia S, Hickish T, et al.: Pertuzumab plus trastuzumab in combination with standard neoadjuvant anthracycline-containing and anthracyclinefree chemotherapy regimens in patients with HER2 positive early breast cancer: A randomized phase II cardiac safety study (TRYPHAENA). Ann Oncol. 2013;24:2278-2284.

4 Liedtke C, Mazouni C, Hess KR, et al.: Response to neoadjuvant therapy and long-term survival in patients with triple-negative breast cancer. J Clin Oncol 2008;26:1275-1281.

5 Cortazar P, Zhang L, Untch M, et al.: Pathological complete response and long-term clinical benefit in breast cancer: the CTNeoBC pooled analysis. Lancet 2014;384:164-172.

6 Berruti A, Amoroso V, Gallo F, et al.: Pathologic complete response as a potential surrogate for the clinical outcome in patients with breast cancer after neoadjuvant therapy: A meta-regression of 29 randomized prospective studies. J Clin Oncol 2014;32:3883-3891.
7 Citron ML: Dose-dense chemotherapy: Principles, clinical results and future perspectives. Breast Care (Basel) 2008;3:251-255.

8 Simon R, Norton L: The Norton-Simon hypothesis: Designing more effective and less toxic chemotherapeutic regimens. Nat Clin Pract Oncol 2006;3:406-407.

9 Norton L: Evolving concepts in the systemic drug therapy of breast cancer. Semin Oncol 1997;24(Suppl 10): S3-10.

10 Coldman AJ, Goldie JH: Impact of dose-intense chemotherapy on the development of permanent drug resistance. Semin Oncol 1987;14(Suppl 4):29-33.

11 Hryniuk W, Levine MN: Analysis of dose intensity for adjuvant chemotherapy trials in stage II breast cancer. J Clin Oncol 1986;4:1162-1170.

12 Untch M, Möbus V, Kuhn W, et al.: Intensive dosedense compared with conventionally scheduled preoperative chemotherapy for high-risk primary breast cancer. J Clin Oncol 2009;27:2938-2945.

13 von Minckwitz G, Raab G, Caputo A, et al.: Doxorubicin with cyclophosphamide followed by docetaxel every 21 days compared with doxorubicin and docetaxel every 14 days as preoperative treatment in operable breast cancer: The GEPARDUO study of the German Breast Group. J Clin Oncol 2005;23:2676-2685.

14 Untch M, von Minckwitz G, Konecny GE, et al.: PREPARE trial. A randomized phase III trial comparing preoperative, dose-dense, dose-intensified chemotherapy with epirubicin, paclitaxel and CMF versus a standard dosed epirubicin/cyclophosphamide followed by paclitaxel \pm darbepoetin alfa in primary breast cancer outcome on prognosis. Ann Oncol 2011;22:1999-2006.
15 Untch M, Fasching PA, Konecny GE, et al.: PREPARE trial: a randomized phase III trial comparing preoperative, dose-dense, dose-intensified chemotherapy with epirubicin, paclitaxel and CMF versus a standard-dosed epirubicin/cyclophosphamide followed by paclitaxel \pm darbepoetin alfa in primary breast cancer - results at the time of surgery. Ann Oncol 2011;22:1988-1998.

16 Therasse P, Mauriac L, Welnicka-Jaskiewicz M, et al.: Final results of a randomized phase III trial comparing cyclophosphamide, epirubicin, and fluorouracil with a dose-intensified epirubicin and cyclophosphamide + filgrastim as neoadjuvant treatment in locally advanced breast cancer: An EORTC-NCIC-SAKK multicenter study. J Clin Oncol 2003;21:843-850.

17 Baldini E, Gardin G, Giannessi PG, et al.: Accelerated versus standard cyclophosphamide, epirubicin and 5-fluorouracil or cyclophosphamide, methotrexate and 5-fluorouracil: A randomized phase III trial in locally advanced breast cancer. Ann Oncol 2003;14:227-232.

18 Green MC, Buzdar AU, Smith T, et al.: Weekly paclitaxel improves pathologic complete remission in operable breast cancer when compared with paclitaxel once every 3 weeks. J Clin Oncol 2005;23:5983-5992.

19 Walker LG, Eremin JM, Aloysius MM, et al.: Effects on quality of life, anti-cancer responses, breast conserving surgery and survival with neoadjuvant docetaxel: A randomised study of sequential weekly versus threeweekly docetaxel following neoadjuvant doxorubicin and cyclophosphamide in women with primary breast cancer. BMC Cancer 2011;11:179. 
20 Sparano JA, Zhao F, Martino S, et al.: Long-term follow-up of the E1199 phase III trial evaluating the role of taxane and schedule in operable breast cancer. J Clin Oncol 2015;33:2353-2360.

21 Ellis GK, Barlow WE, Gralow JR, et al.: Phase III comparison of standard doxorubicin and cyclophosphamide versus weekly doxorubicin and daily oral cyclophosphamide plus granulocyte colony-stimulating factor as neoadjuvant therapy for inflammatory and locally advanced breast cancer: SWOG 0012. J Clin Oncol 2011;29:1014-1021.

$22 \mathrm{https} / /$ clinicaltrials.gov/ct2/results?term=geparOcto\& Search=Search.

23 von Minckwitz G, Schneeweiss A, Loibl S, et al.: Neoadjuvant carboplatin in patients with triple-negative and HER2-positive early breast cancer (GeparSixto; GBG 66): A randomised phase 2 trial. Lancet Oncol 2014;15:747-756.
24 von Minckwitz G, Loibl S, Schneeweiss A, et al.: S2-04. Early survival analysis of the randomized phase II trial investigating the addition of carboplatin to neoadjuvant therapy for triple-negative and HER2-positive early breast cancer (GeparSixto). SABCS 2015.

25 Sikov WM, Berry DA, Perou CM, et al.: S2-05. Eventfree and overall survival following neoadjuvant weekly paclitaxel and dose-dense AC $+/$ - carboplatin and/or bevacizumab in triple-negative breast cancer: Outcomes from CALGB 40603 (Alliance). SABCS 2015.

26 Moebus V, Jackisch C, Lueck HJ, et al.: Intense dosedense sequential chemotherapy with epirubicin, paclitaxel, and cyclophosphamide compared with conventionally scheduled chemotherapy in high-risk primary breast cancer: Mature results of an AGO phase III study. J Clin Oncol 2010;28:2874-2880.
27 Korn EL, Sachs MC, McShane LM: Statistical controversies in clinical research: Assessing pathologic complete response as a trial-level surrogate end point for early-stage breast cancer. Ann Oncol 2016;27:10-15.

28 Early Breast Cancer Trialists' Collaborative Group (EBCTCG), Dowsett M, Forbes JF, et al.: Aromatase inhibitors versus tamoxifen in early breast cancer: Patient-level meta-analysis of the randomised trials. Lancet 2015;386:1341-1352.

\section{Erratum}

Breast Care 2016;11:20

DOI: $10.1159 / 000444652$

In the article

Taxanes Plus Trastuzumab Compared To Oral Vinorelbine Plus Trastuzumab in HER2-Overexpressing Metastatic Breast Cancer Bergen E, Berghoff A.S, Rudas M, Dubsky P, De Vries C, Sattlberger C, Mader R.M, Zagouri F, Sparber C, Fitzal F, Gnant M, Rottenfusser A, Zielinski CC, Preusser M, Steger G.G, Bartsch R.

Breast Care 2014;9:344-348 (DOI:10.1159/000368330)

Figures 1 and 2 were identical.

The correct fig. 2 is the following:

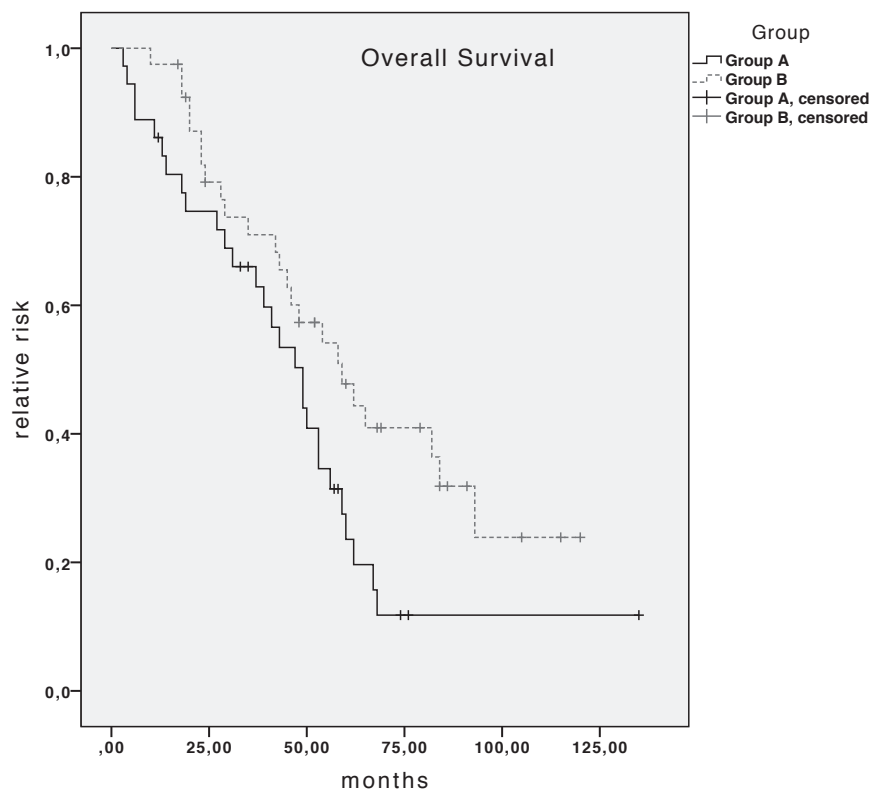

Fig. 2. Kaplan-Meier estimates for overall survival (OS). Median OS in patients receiving taxanes plus trastuzumab (group A) was 49 months (95\% CI, 38.24-59.76) and 59 months (95\% CI, 41.17-76.83) in patients receiving oral vinorelbine plus trastuzumab (log-rank test; $\mathrm{p}=0.033$ ). 